\title{
Neuro-oncology 2021
}

\author{
Silvia Hofer
}

In this issue of memo (Magazine of European Medical Oncology), you will find two review articles: one on the current management of brain metastases [1] and a second one on leptomeningeal metastases [2]. Both disease manifestations of solid tumors have gained interest, mostly due to an increasing number of affected patients, an improved pathophysiological understanding and, most importantly, advances in diagnostic and therapeutic approaches. A valuable addition to the two previously mentioned articles is a statement by Dieckmann and Herrmann on the role of whole-brain radiation therapy (WBRT) in these tumor manifestations. Impressive neurocognitive deteriorations already 3 months after and increasingly in the first year after WBRT limit the indication of this modality in favour of focused irradiation or targeted therapy in accordance with the tumor entity [3].

Major changes in the 5th edition of the World Health Organization classification of central nervous system (CNS) tumors will be published in 2021. A brief preview of the anticipated changes will be presented in this memo issue [4]. It is based on seven cIMPACT (Consortium to Inform Molecular and Practical Approaches to CNS Tumor Taxonomy) publications and recent literature. The changes will have a great im- pact on the day-to-day work of neuro-oncologists and basic features should be known to all oncologists.

Conflict of interest S. Hofer declares that she has no competing interests.

\section{References}

1. Berghoff A, Steindl A. Brain metastases: new systemic treatment approaches. memo. 2021. https://doi.org/10. 1007/s12254-021-00709-1.

2. Hofer S, Le Rhun E. Leptomeningeal metastases from solid tumours. memo. 2021. https://doi.org/10.1007/s12254021-00693-6.

3. Dieckmann K, Herrmann H. Are there still indications for whole brain irradiation in 2021? memo. 2021. https://doi. org/10.1007/s12254-021-00710-8.

4. Rushing EJ. WHO classification of tumors of the nervous system: preview of the upcoming 5th edition. memo 2021. https://doi.org/10.1007/s12254-021-00680-x.

Publisher's Note Springer Nature remains neutral with regard to jurisdictional claims in published maps and institutional affiliations. 